\title{
MRS University Chapter Special Project Awards
}

\author{
mrs.org/foundation-university-chapter-special-projects
}

$\mathrm{T}$ he Materials Research Society (MRS) University Chapters Program is a network of students from universities around the world that fosters an environment of collaboration and open exchange of ideas across all scientific disciplines.

Each year, MRS offers current University Chapters an opportunity to organize community events that broaden awareness of materials science education by way of the University Chapters Special Projects Program. Grant funding is dedicated to supporting projects proposed by Chapters, and projects are evaluated against the following criteria:

- Project is a new initiative and not a continuation or expansion of a present activity.

- Project is clearly initiated by students and addresses a well-defined need.

- Measurable outcomes/deliverables are clearly stated.

- Timeline and plan for successful completion are clear and realistic.

- Funding request and proposed budget are reasonable.

- Deliverables are potentially useful to other University Chapters or to MRS in general.
The Chapter must be current, active, and in good standing. Funding ranges from USD \$250-\$1,000 per project. The following are Chapters that have received 2019 grants.

\section{African University of Science and Technology MRS Research Communication and Career Day}

The MRS University Chapter at the African University of Science and Technology, Abuja, is organizing a research communication and career day event for graduate students studying materials science and engineering, physics, mathematics, and computer science. Over the years, researchers have created good research ideas and, in most cases, good research results, but they are limited in skill to properly analyze their results, write manuscripts, or present their research. This event intends to expose graduate students and other interested students to the role of effective communication in research, and the opportunities and challenges in different careers and ways to excel.

This program will sponsor a one-day workshop/seminar to enlighten students

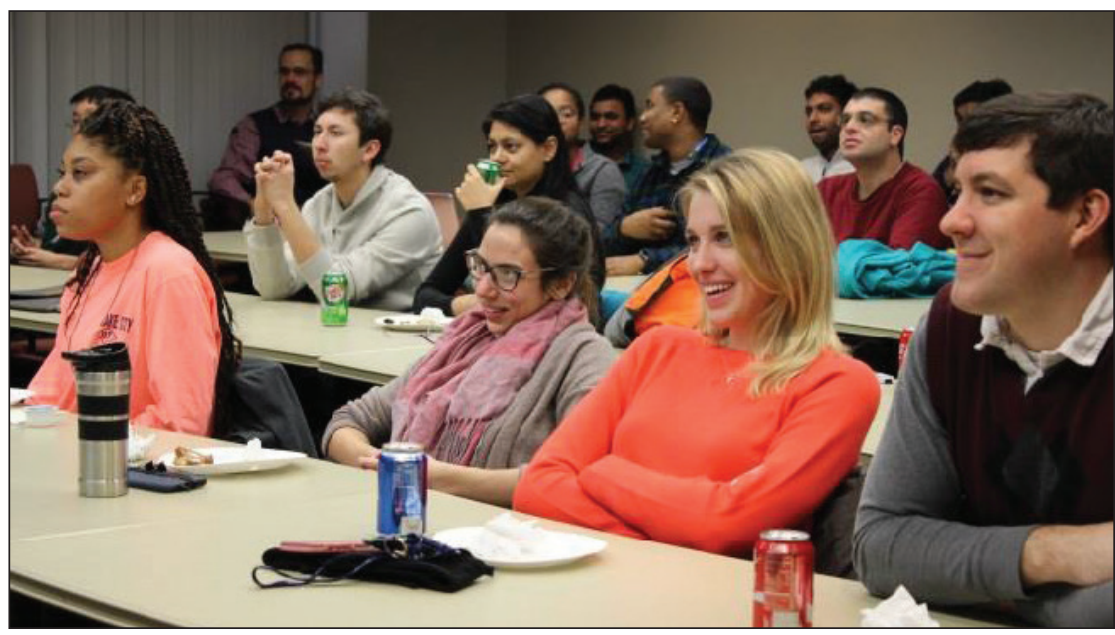

Undergraduate students attended a fun, freestyle question and answer session presented by graduate students about their research and labs as part of the "Chic and Fun Lab Contest" submitted by 2017 MRS University Chapter grant recipient, University of Connecticut.

from Abuja and neighboring communities about the need for effective research communication, to teach the skills required for technical writing, and to provide the proper and most recent tools for result analysis and effective presentation skills. Professionals from different fields and career sectors (academia, research, industry, government, business) will be invited to interact and network with students and to provide mentorship and career counseling services. Finally, there will be a paper contest among members where awards will be given to the top three students with an encouraging knowledge of research and communication.

\section{Binghamton University Binghamton Materials Science Outreach Program}

The MRS University Chapter at Binghamton University (BU), in collaboration with the Binghamton University Chemistry Outreach Program (ChOP) and Physics Outreach Program (POP), will train graduate and undergraduate students from the MRS BU Chapter and volunteers from ChOP and POP to design and facilitate hands-on materials science activities for young students. By designing and engineering new outreach activities, undergraduate and graduate students will have the opportunity to test and reinforce concepts, which will increase their interest in materials science research, solidify their knowledge, and increase self-efficacy. With the help of MRS BU Chapter volunteers, ChOP and POP will use these materials science activities during multiple school visits and at a shopping mall outreach event during the Spring 2019 semester. The activities will enable the volunteers to promote materials science to young students at a basic level, which will introduce the students to materials science, develop their interest, and help them build a strong scientific foundation.

This outreach project also promotes research and enhances teaching interest among undergraduate and graduate stu- 
dents, encouraging them to pursue a career in materials science. Overall, this project will result in a cross-generational increase in materials science awareness. Each outreach event will run for approximately two hours, and approximately seven events will be held from February through May 2019.

\section{Boston University \\ Boston University Materials Science Olympics}

The MRS University Chapter at Boston University will host the "Materials Science Olympics," in which Chapter members and students from other departments compete in teams of four in materials science-related challenges. The goal is to help foster relationships between materials science students and other graduate students conducting materials science-related research at Boston University. These challenges will be based on materials topics spanning mechanical properties of materials, fluids and surface energy, and polymer elasticity.

\section{Northwestern University MSUS Student Lecture Series}

The "Materials Science Umbrella Society (MSUS) Student Lecture Series" will feature five lectures presented by graduate students in Northwestern's Materials Science and Engineering Department over the course of 2019. The lecturers will present the fundamental concepts underlying their research. For example, students working on electronic materials can lead a lecture about electron and hole mobility, how impurities affect these mobilities, and then show examples they encountered in their research. The style of these lectures is similar to "chalk talks" that are often presented in other natural science disciplines. The lectures will vary in length, depending on the content, with time for questions and discussion.

To kick-start the lecture series, Northwestern University students plan to host a workshop on how to effectively present a lecture. In addition, the MSUS team will work with the lecturer to prepare a clear, well-thought-out lecture. A discussion will be held on implementing the tips for effective presentations and oration discussed in the initial workshop.

\section{Oklahoma State University Introduction to Materials Science and Application of Python in the Development of Novel Materials} The MRS University Chapter of Oklahoma State University (OSU) at Tulsa will organize a workshop on the Introduction to Materials Science and Application of Python in the Development of Novel Materials for high-school students in the

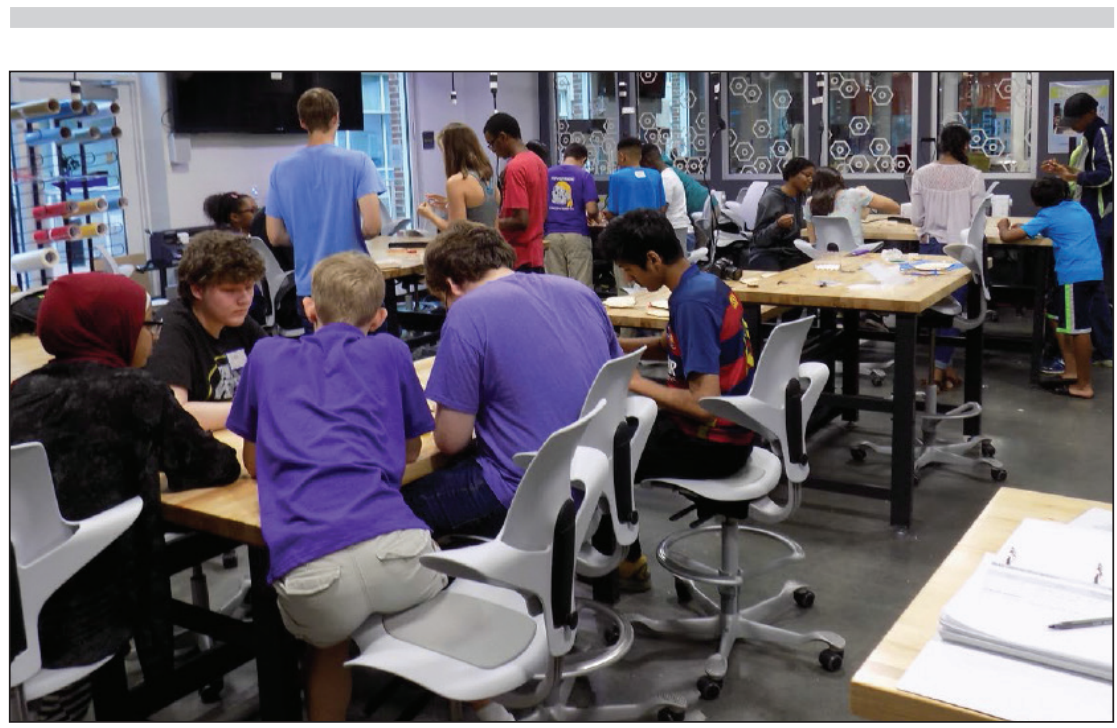

High-school students from lower-income districts completed a circuit building challenge to light up an LED map. This was one of many activities held during "Materials Science Day," a grant project presented by the MRS University Chapter at The University of North Carolina at Chapel Hill in 2017.
Tulsa region. They will collaborate with experts in Python programming from the region to introduce students to the latest developments in materials science and the use of computing for novel materials development.

On the first day of the two-day workshop, students will receive a tour of the state-of-the-art research facility for materials research at OSU, followed by scientific demonstrations and talks given by graduate students and faculty. On the second day, students will be introduced to the application of Python programming for materials research.

\section{University of Cologne} National Laboratory User Facilities: How to Get Access for Your Research The MRS University Chapter at the University of Cologne together with the MRS University Chapter at Drexel University, the MRS University Chapter at The City University of New York, and members from the student chapters at Sociedad Mexicana de Materiales-Mexico are organizing a pre-conference event at the 2019 MRS Spring Meeting in Phoenix (April 22, 2:00-5:00 pm) to provide an informative session on their user facilities.

The major aim is to explain to students and young professionals how to use the facilities, including how to get access, contact corresponding personnel, and planning for traveling and housing during measurements. Representatives from US user facilities will present their state-of-the-art equipment and explain the measurement application process.

\section{University of Connecticut MRS Special Project Program of the University of Connecticut Chapter}

The University of Connecticut will introduce a collaborative graduate student seminar series in which graduate students from a neighboring MRS University Chapter will visit the University of Connecticut and present their research in an invited speaker seminar environment. They will collaborate with MRS members to give presentations about similar topics, comparing and discussing different research aspects and advantages. 
This seminar series will allow students involved in research in materials science and related fields to foster professional relationships with members of their scientific community and possibly motivate research collaborations between the University of Connecticut and institutions from which the visiting students are associated.

Students will have an opportunity to visit industrial sites (Pratt and Whitney, Sikorsky Aircraft, Stanadyne LLC, United Technologies Corporation) and/or national laboratories (Brookhaven National Laboratory), which will provide the knowledge necessary for making informed decisions about pursuing a career in these areas. Preexisting industrial collaborations assist in the organization of campus tours, allowing undergraduate and graduate students increased exposure to a diverse field and, ultimately, illustrating the industrial and national laboratory aspects of materials research.

\section{University of Houston University of Houston MRS Chapter Student Symposium}

The University of Houston will organize their third annual student symposium highlighting research in materials science conducted across several departments at the University of Houston (UH) and other universities outside of UH. The event will provide a platform for students to interact, network, disseminate, and showcase their research work through oral and poster presentations, and will create opportunities for students and faculty inside and outside of UH to collaborate and create partnerships. Furthermore, the student symposium is designed to raise awareness of cuttingedge materials science research activities performed at several research laboratories.

\section{University of Kentucky Kentucky Materials Networking Day}

The University of Kentucky will host the "Kentucky Materials Networking Day" to promote collaboration and networking among materials-focused research groups in Lexington and the surrounding area. Networking and collaboration are essential to promoting quality and impactful materials research.

By hosting a one-day materials symposium open to various departments at the University of Kentucky and neighboring universities, Chapter students aim to increase collaboration and enhance the quality of materials research from the state of Kentucky. Research groups from universities with fewer resource opportunities can make connections with other universities that have access to instruments and facilities. This event will also allow students to meet other researchers working on similar projects to discuss the challenges they face and strategies to approach them. A poster session will allow more students the opportunity to present and will facilitate discussions among researchers. This event will highlight research and other opportunities for undergraduate students and high-school teachers.

\section{The University of North Carolina at Chapel Hill Undergraduate Outreach Program Co-organized by Future Chemistry Faculty at PUls}

The MRS University Chapter and the Future Chemistry Faculty at PUIs (FCFP) organization at The University of North Carolina at Chapel Hill (UNC-CH) will organize four panel and Q\&A style outreach events at primarily undergraduate institutions (PUIs) in North Carolina.
Graduate students from MRS and FCFP will visit these schools to give brief overviews of how they decided to pursue $\mathrm{PhD}$ degrees in science and engineering, why they are interested in being professors at PUIs (for FCFP members), why they pursue materials research, and why outreach is important (for MRS members). This will provide a broad sense of the possible career choices available after graduate school for science and engineering $\mathrm{PhD}$ students. Presentations will give a sense of the types of research that are completed at R1 research institutions. These discussions will also communicate what graduate school is like and career goals. These efforts will increase the awareness of students at PUIs about pursuing a $\mathrm{PhD}$ degree.

The overarching goal of the outreach program is to encourage students of all backgrounds that a career in science and engineering is possible for everyone, and this will motivate them toward pursuing research both at their current education stage and in the future. More than 10 PUIs in the area that would benefit from the program have been identified.

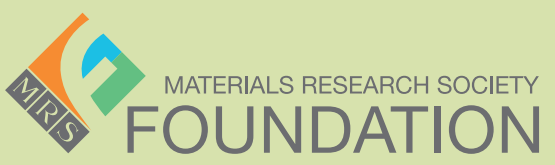

MATERIALS RESEARCH SOCIETY
For more information on MRS University Chapter Special Projects and/or how to submit a proposal, visit mrs.org/foundation-university-chapter-special-projects. 